Journal of Mechanical Engineering and Sciences (JMES)

ISSN (Print): 2289-4659; e-ISSN: 2231-8380; Volume 4, pp. 452-461, June 2013

(C) Universiti Malaysia Pahang, Pekan, Pahang, Malaysia

DOI: http://dx.doi.org/10.15282/jmes.4.2013.9.0042

\title{
HEAT TRANSFER ENHANCEMENT WITH NANOFLUIDS - A REVIEW
}

\author{
A.M. Hussein, K.V. Sharma, R.A. Bakar and K. Kadirgama \\ Faculty of Mechanical Engineering \\ Universiti Malaysia Pahang, 26600 Pekan, Pahang, Malaysia \\ Email: adnanphd2012@gmail.com
}

\begin{abstract}
This paper presents a review of the studies undertaken on convection heat transfer with nanofluids. Initial studies were directed towards the determination of the properties of nanofluids, especially their thermal conductivity and viscosity. The studies indicate that thermal conductivity and viscosity increase with an increase in the concentration of the nanofluid. Experiments were conducted with different nanofluids, at various concentrations and temperature ranges, for the estimation of the heat transfer coefficient and friction factor for water-based nanofluids. All the studies confirmed enhancement of the heat transfer coefficient with an increase in concentration. The experimental ranges of temperature undertaken by the authors were different for different nanofluids. Certain studies with smaller particle sizes indicated an increase in heat transfer enhancements when compared with values obtained when using larger particle sizes. It is observed that the concentration of the nanofluid, the operating temperature, the particle size and shape, together with the material of the nanoparticle dispersed in the base liquid, have significant influence on the heat transfer coefficient. All the studies indicate a nominal increase in pressure drop.
\end{abstract}

Keywords: Convection heat transfer; thermal conductivity; viscosity; friction factor; nanofluid.

\section{INTRODUCTION}

A nanofluid is prepared by dispersing particles of metal or metal oxide with sizes of 100 $\mathrm{nm}$ or less, in a base liquid such as water. The purpose of using nanofluids is to achieve higher values of heat transfer coefficient compared with that of the base liquid. This is achieved by the dispersion of solid particles, which have higher thermal conductivity than the base liquid. There are many engineering applications that can benefit from the use of nanofluids, for example absorption refrigeration, micro electromechanical systems, lubrication of automotive systems, the manufacture of advanced miniature camera lenses, coolant in machining, automobile radiator cooling, personal computers, solar water heating, heat exchangers, several medical applications, nuclear reactors, and in several aerospace applications. Recent advances in material technology have made it possible to produce innovative heat transfer fluids by suspending nanometer-sized particles in base fluids, which could change the transport and thermal properties of the liquids. Nanofluids represent solid-liquid composite materials consisting of solid nanoparticles with sizes no larger than $100 \mathrm{~nm}$ suspended in liquid (Ferrouillat, 2011). This study presents the work undertaken by various investigators and the possible impact of nanofluids on the enhancement of heat transfer in the near future. 


\section{THERMAL PROPERTIES OF NANOFLUIDS}

The thermal properties of nanofluids have received significant attention. Nanofluids are considered to offer important advantages over conventional heat transfer fluids. A number of experimental studies to investigate the transport properties of nanofluids have been carried out (Choi, 1995; Masuda, Ebata, Teramae, \& Hishinuma, 1993; Eastman, Choi, Li, Thompson, \& Lee, 1997; Lee, Choi, Li, \& Eastman, 1999). Many researchers have used regression equations of density and specific heat capacity (Gianluca, 2012; Heris, Etemad, \& Esfahany, 2006; Incropera \& DeWitt, 1996; Kulkarni, Namburu, Ed Bargar, \& Das, 2008; Lee et al, 1999; Li \& Xuan, 2002; Ma, Wilson, Borgmeyer, Park, \& Yu, 2006; Masuda et al, 1993; Namburu, Kulkarni, Misra, \& Das, 2007) as:

$$
\begin{gathered}
\rho_{\mathrm{nf}}=\left(\frac{\phi}{100}\right) \rho_{p}+\left(1-\frac{\phi}{100}\right) \rho_{f} \\
C_{n f}=\frac{\frac{\phi}{100}(\rho C)_{p}+\left(1-\frac{\phi}{100}\right)(\rho C)_{f}}{\rho_{n f}}
\end{gathered}
$$

\section{Thermal Conductivity}

The thermal conductivity of nanofluids was found to increase with concentration (Pak \& Cho, 1998; Xuan and Li 2000; Xuan \& Roetzel, 2000; Xue, Keblinski, Phillpot, Choi, \& Eastman, 2004; Heris et al., 2006) following experiments undertaken with $\mathrm{Cu}, \mathrm{Al}_{2} \mathrm{O}_{3}$, $\mathrm{CuO}$, and $\mathrm{TiO}_{2}$ nanoparticles in water, they also, observed heat transfer enhancement as high as $40 \%$ with $\mathrm{Al}_{2} \mathrm{O}_{3}$ particles. A simulation of the effective thermal conductivity of nanofluids through modeling has been undertaken by Bhattacharya, Saha, Yadav, Phelan, \& Prasher (2004). Nanoparticles dispersed in ethylene glycol (EG), water $\left(\mathrm{H}_{2} \mathrm{O}\right)$ and oil have shown an increase in the thermal conductivity ratio $\left(\mathrm{k}_{\mathrm{nf}} / \mathrm{k}_{\mathrm{f}}\right)$ with a decrease in the thermal conductivity values of the base fluid (Lee et al., 1999). With regard to the volume concentrations and magnitude of particle-particle interaction that are affected by $\mathrm{pH}$, surfactant additives, and particle size and shape, agglomeration equilibrium is established in nanoparticle suspension. It should be noted that two types of agglomeration are possible in nanofluids. The first type of agglomeration occurs when nanoparticles are agglomerated through the solid-solid interface, which can potentially provide increased thermal conductivity, as described by Prasher, Wang, and Phelan (2006). The $\mathrm{SiC}$ in water and EG/water mixed with volume concentration and $\mathrm{pH}$ was studied by Timofeeva, Yu, France, Singh, and Routbort (2010). It showed that the change in thermal conductivity ratio was 5\% higher in EG/water than in water considering all other parameters. The base fluid effect, observed with different nanofluid systems, is most likely related to the lower value of the thermal resistance in the EG/water than in the water-based nanofluids. Both thermal conductivity and viscosity are related strongly to the nanofluid microstructure. The nanoparticles dispersed in a base fluid are in random motion under the influence of several forces such as Brownian motion, intermolecular van-der-Waals interaction (repulsion, polarization, and dispersion forces), and electrostatic interactions between ions and dipoles. Thermal conductivity measurement of pure fluids by the transient hot-wire method has been investigated (Wang, 2009). A transient hot wire is in contact with the 
liquid being studied (Pawan, Singh, \& Anoop, 2010; Gianluca, 2012) and the effect of temperature on thermal conductivity is shown in Figure 1. The thermal conductivity of nanofluids has been found experimentally, and data of the thermal conductivity for metal and metal oxides, such as $\mathrm{Al}_{2} \mathrm{O}_{3}, \mathrm{Fe}_{3} \mathrm{O}_{4}, \mathrm{TiO}_{2}, \mathrm{ZnO}, \mathrm{ZrO}_{2}$, and $\mathrm{CuO}$ nanofluids, available in the literature, have used in the development of the regression Eq. (3).

$$
k_{r}=\frac{k_{n f}}{k_{f}}=\left\{0.8938\left(1+\frac{\phi}{100}\right)^{1.37}\left(1+\frac{T_{n f}}{70}\right)^{0.2777}\left(1+\frac{d_{p}}{150}\right)^{-0.0336}\left(\frac{\alpha_{p}}{\alpha_{f}}\right)^{0.01737}\right.
$$

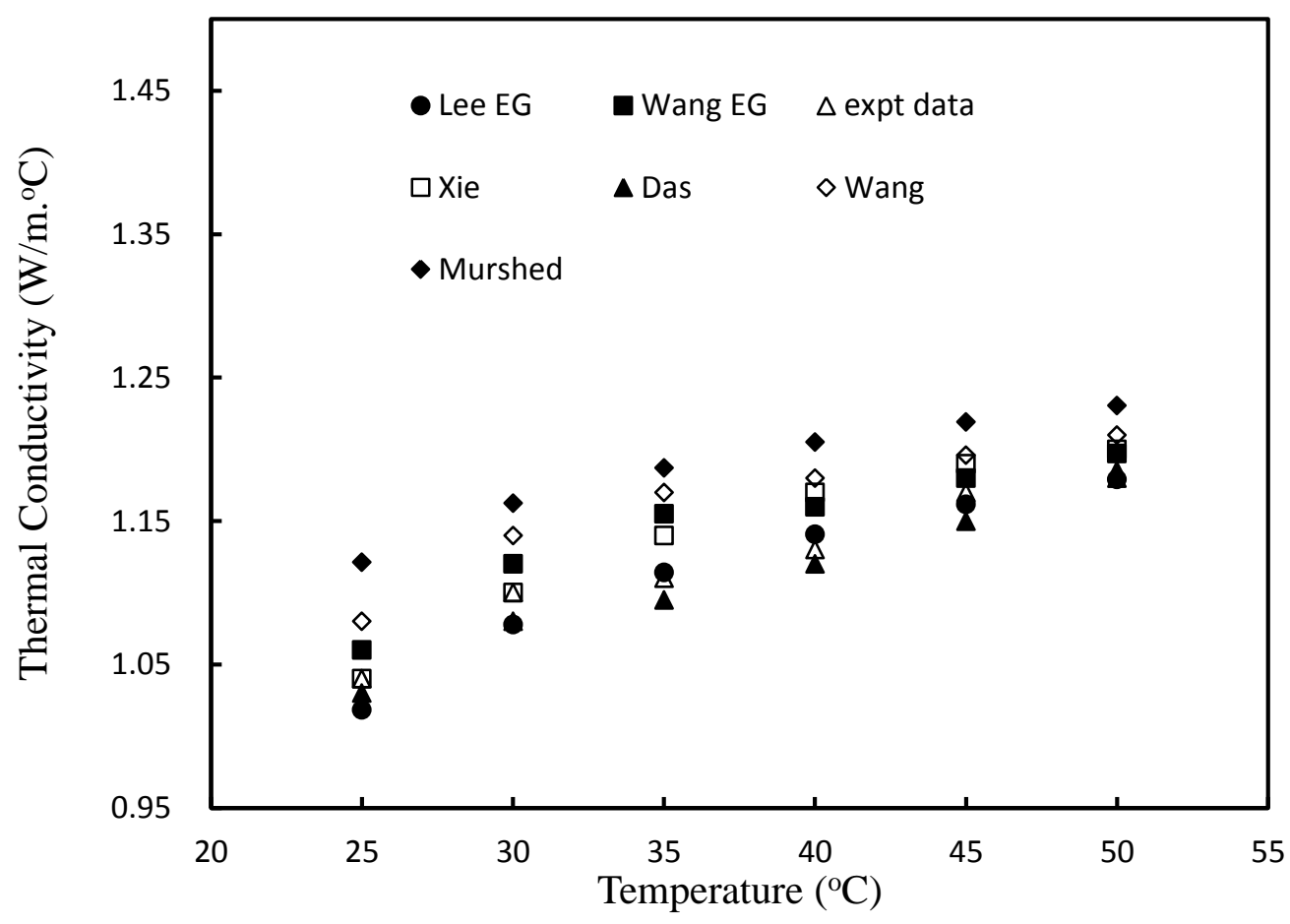

Figure 1. Effect of temperature on thermal conductivity.

\section{Viscosity}

Rheometers are used to measure the rheological properties of nanofluids (Ding et al., 2006; Prasher et al., 2006). The viscosity has been shown to decrease with an increase in the average diameter size in both EG/water and water-based suspensions. However, at the same volume concentration of nanoparticles, the relative viscosity increase was smaller in EG/water than in the water-based nanofluids, especially in suspensions of smaller nanoparticles (Timofeeva et al., 2010). According to the classic Einstein equation for hard non-interacting spheres (Vold, Kristiansen, \& Christensen, 2007), the viscosity increase should be independent of the viscosity of the base fluid and only proportional to the volume concentration. Viscometers have been used by Nguyen, Desgranges, Galanis, Roy, Mare, Boucher, \& Angue (2008), Namburu et al. (2007), and Pozhar (2000) who studied the effect of nanofluid concentration on viscosity (Figure 2). The experimental data of viscosity obtained at $4 \%$ volume fraction, consisting of many data points, was subjected to regression and the following correlation obtained. 


$$
\mu_{r}=\frac{\mu_{n f}}{\mu_{f}}=\left(1+\frac{\phi}{100}\right)^{11.3}\left(1+\frac{T_{n f}}{70}\right)^{-0.038}\left(1+\frac{d_{p}}{170}\right)^{-0.061}
$$

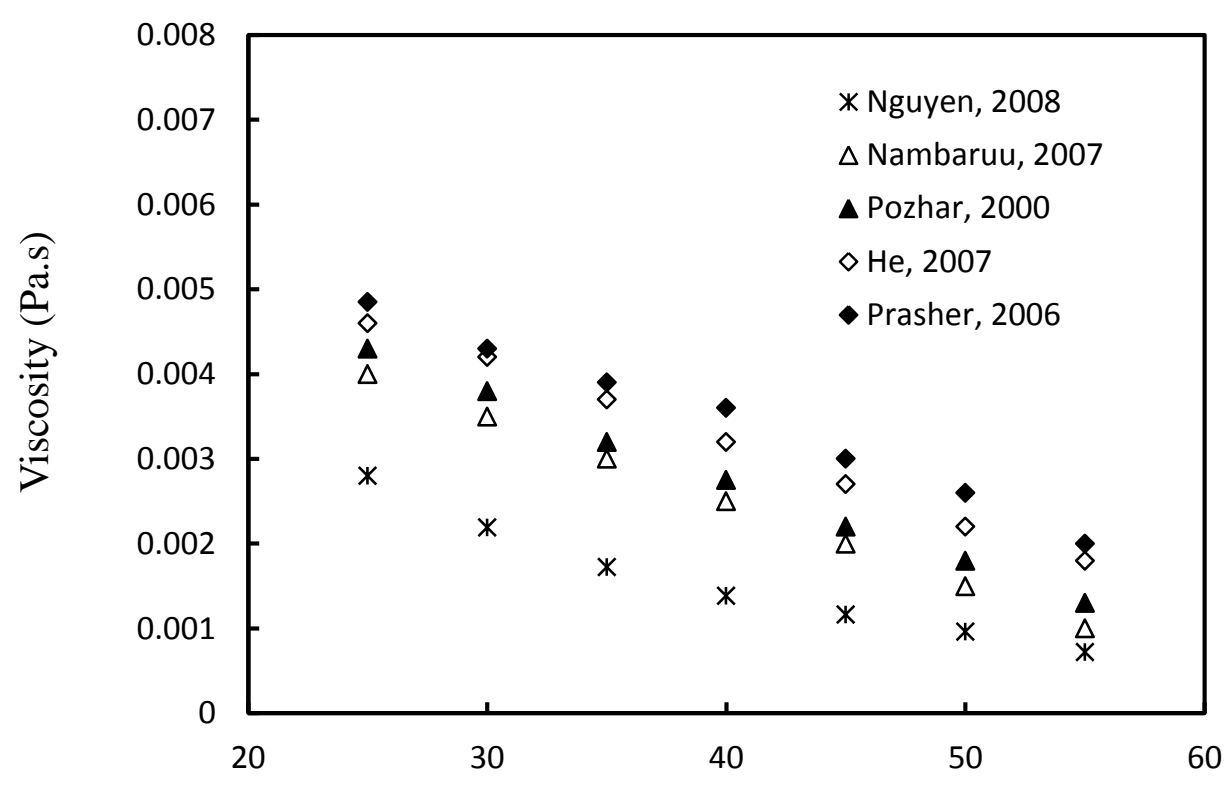

Temperature $\left({ }^{\circ} \mathrm{C}\right)$

Figure 2. Effect of temperature on viscosity.

\section{Friction Factor}

Turbulent friction factors have been evaluated for the flow of nanofluids in a tube (Pak \& Cho, 1998; Xuan \& Li, 2002; Yang, Zhang, Grulke, Anderson, \& Wu, 2005; Ding et al., 2006; Ma et al., 2006; Kulkarni et al., 2008). Some of the studies are in agreement with values estimated by using the Blasius equation:

$$
f=\frac{0.316}{\operatorname{Re}^{0.25}} \quad \text { For } \quad \operatorname{Re}>1 \times 10^{4}
$$

The calculated friction factors were then compared for validation (Incropera \& DeWitt, 1996; Dong \& Leyuan, 2010). Figure 3 shows the friction factors at different Reynolds numbers.

\section{HEAT TRANSFER ENHANCEMENT}

Numerical studies of steady-state turbulent convection of a water- $\mathrm{Al}_{2} \mathrm{O}_{3}$ nanofluid inside a circular tube, by means of the finite volume method, has been investigated by many researchers (Li, 2002; Bianco \& Manca, 2011; Syam Sundar \& Sharma, 2011a,b; Rao, Sharma, Chary, Bakar, Rahman, Kadirgama, \& Noor, 2011), and the results showed that heat transfer is enhanced with particle volume concentration and Reynolds number. A study of forced convection heat transfer of nanofluids inside a horizontal circular tube, subjected to a constant and uniform heat flux at the wall, was carried out 
by Shuichi (2012), and the results showed that the heat transfer enhancement was caused by the suspended nanoparticles. A bibliography of works on experimental forced convective heat transfer with nanofluids with $\mathrm{Al}_{2} \mathrm{O}_{3}$ particles and $\mathrm{TiO}_{2}$ particles at the same concentration levels is presented in Table 1. When taking into account thermal conductivity, it is not surprising that the $\mathrm{Cu}$-water nanofluid shows the highest heat transfer enhancement. However, the thermal conductivity enhancements of $\mathrm{Al}_{2} \mathrm{O}_{3}$ and $\mathrm{TiO}_{2}$ in water are similar, although the heat transfer enhancement of $\mathrm{Al}_{2} \mathrm{O}_{3}$ in water is higher than that of $\mathrm{TiO}_{2}$ in water.

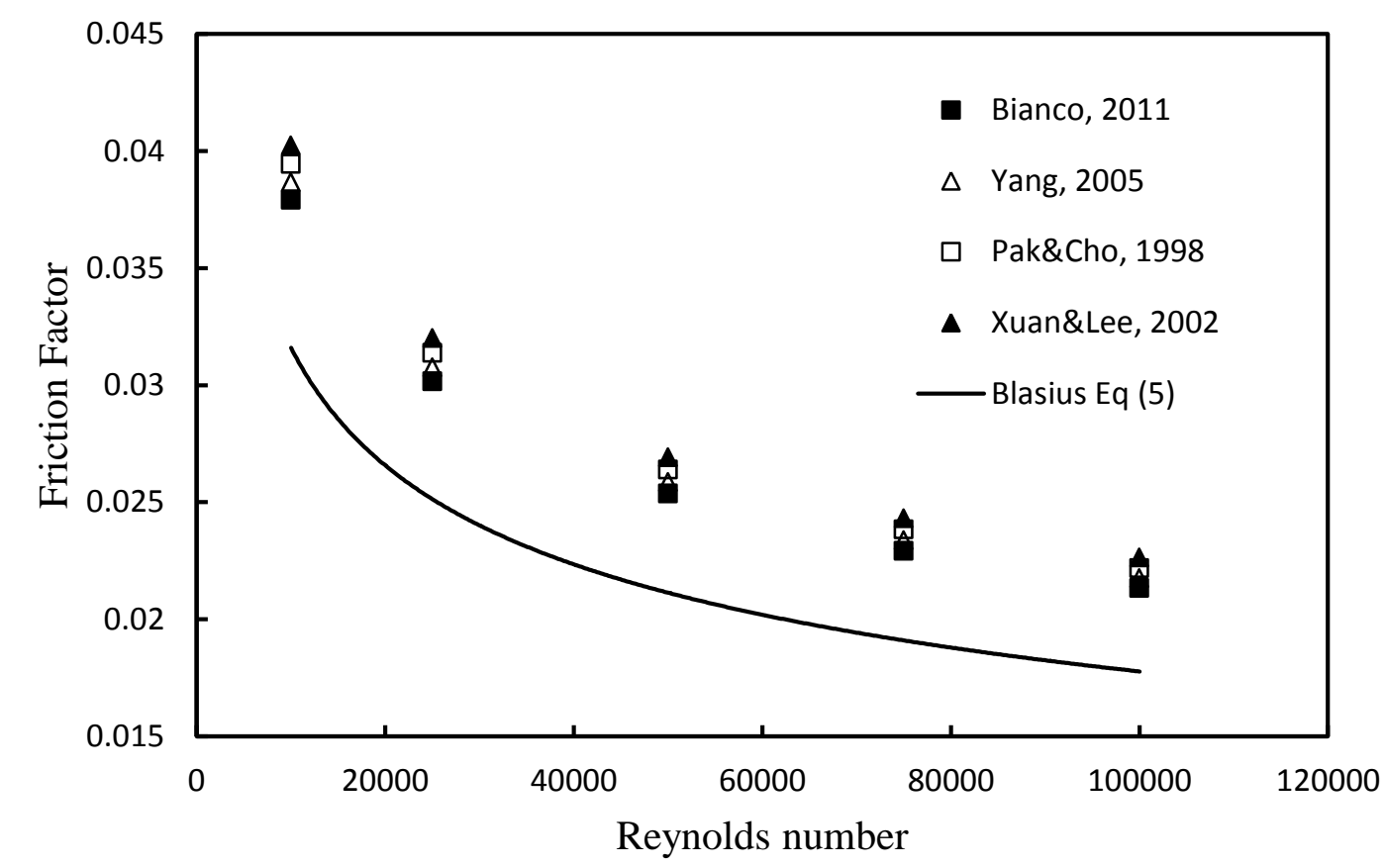

Figure 3. Friction factor at different Reynolds number.

However, two groups found that the heat transfer coefficient of nanofluids $\left(\mathrm{Al}_{2} \mathrm{O}_{3}\right.$ and $\mathrm{TiO}_{2}$ in water and $\mathrm{SiC}$ in water) was lower than for pure water for constant average velocity in a turbulent flow (Ferrouillat, 2011; Vijaya Lakshmi, Subrahmanyam, Dharma Rao, \& Sharma, 2012). A hybrid nanofluid was used to enhance the heat transfer and pressure drop in a fully developed laminar flow through a uniformly heated circular tube (Suresh, Venkitaraj, Selvakumar, \& Chandrasekar, 2012). Experimental results using $\mathrm{Cu}-\mathrm{Al}_{2} \mathrm{O}_{3}$ in water synthesized with $0.1 \%$ volume concentration showed a maximum enhancement of $13.56 \%$ in the Nusselt number at a Reynolds number of 1730 when compared to the Nusselt number of water. Results also showed that $0.1 \% \mathrm{Cu}-\mathrm{Al}_{2} \mathrm{O}_{3} /$ water nanofluids have a slightly higher friction factor when compared with $0.1 \% \quad \mathrm{Al}_{2} \mathrm{O}_{3}$-water nanofluid. Correlations of the Nusselt number and friction factor were found and there was good agreement with the experimental data of other researchers. A number of studies concluded that heat transfer enhancement depends on the Dittus-Boelter equation (Eq. (6)):

$$
N u=0.032 \times \operatorname{Re}^{0.8} \times \operatorname{Pr}^{n}
$$


where $n$ is 0.4 at heating and 0.3 at cooling. The increase in heat transfer coefficient in the turbulent flow of a nanofluid in a tube was reported by Pak \& Cho (1998). They showed the increase was $45 \%$ with $1.34 \%$ volume fraction of $\mathrm{Al}_{2} \mathrm{O}_{3}$ in water, and $75 \%$ with a nanoparticle loading of $2.78 \%$. They predicted that the Nusselt number was a function of the Reynolds number and Prandtl number.

$$
N u=0.021 \times \operatorname{Re}^{0.8} \times \operatorname{Pr}^{0.5}
$$

Xuan and Li (2002) followed Pak and Cho (1998) in showing that an increase of as much as $40 \%$ could be achieved in the heat transfer coefficient of a nanofluid. The correlation of the convection heat transfer coefficient of nanofluids in a horizontal tube was found to be:

$$
N u=0.4328\left(1.0+11.285 \phi^{0.75} P e^{0.218}\right) \operatorname{Re}^{0.333} \operatorname{Pr}^{0.4}
$$

\begin{tabular}{|c|c|c|c|}
\hline Ref. & Nanofluid & $\operatorname{Re}$ & $\mathrm{Nu}_{\mathrm{nf}} / \mathrm{Nu}_{\mathrm{f}}$ \\
\hline Lee \& Choi (1996) & $\begin{array}{l}\text { Metallic nanoparticle } \\
\text { suspension }\end{array}$ & Laminar & $+100 \%$ \\
\hline Pak \& Cho (1998) & $\begin{array}{l}\mathrm{Al}_{2} \mathrm{O}_{3}-\text { water } \mathrm{TiO}_{2}- \\
\text { water } 3 \text { vol. } \%\end{array}$ & Turbulent & $\begin{array}{l}3 \% \text { to } \_12 \% \text { for constant } \\
\text { average velocity }\end{array}$ \\
\hline Li \& Xuan (2002) & $\mathrm{Cu}$-water 2 vol. $\%$ & $800-23,000$ & $60 \%$ \\
\hline Xuan \& Li (2002) & $\mathrm{Cu}-$ water $0.3-2$ vol. $\%$ & $\begin{array}{l}\text { Laminar, } \\
\text { turbulent }\end{array}$ & $30 \%$ \\
\hline Wen \& Ding (2004) & $\mathrm{Al}_{2} \mathrm{O}_{3}$-water $0.2-1.6 \%$ & $650-2050$ & $\begin{array}{l}\mathrm{Nu}>\mathrm{Nu} \text { Shah especially } \\
\text { near the entrance }\end{array}$ \\
\hline Yang et al. (2005) & Graphite $2-2.5$ wt.\% 5 & 110 & $\begin{array}{l}\mathrm{N}_{\mathrm{unf}} / \mathrm{N}_{\mathrm{uf}}<\mathrm{k}_{\mathrm{nf}} / \mathrm{k}_{\mathrm{f}} \text { (aspect } \\
\text { ratio } L / d=0.02)\end{array}$ \\
\hline Ding et al. (2006) & $\begin{array}{l}\text { CNT-water (aspect ratio } \\
>100 \text { ) } 0.1-1 \text { wt. } \%\end{array}$ & $800-1200$ & $+350 \%$ \\
\hline $\begin{array}{l}\text { Zeinali, Esfahany \& } \\
\text { Etemad (2007) }\end{array}$ & $\begin{array}{l}\mathrm{Al}_{2} \mathrm{O}_{3} \text {-water } 0.2-2.5 \\
\text { vol.\% }\end{array}$ & $700-2050$ & $\begin{array}{l}\text { Enhancement of with } \mathrm{Pe} \\
\text { increases with aspect ratio } \\
\text { (nanoparticle shape) }\end{array}$ \\
\hline $\begin{array}{l}\text { Rea, McKrell, Hu \& } \\
\text { Buongiorno (2009) }\end{array}$ & $\begin{array}{l}\mathrm{Al}_{2} \mathrm{O}_{3} \text {-water } 0.6-6.0 \\
\text { vol.\% } \mathrm{ZrO}_{2} \text {-water } 0.32- \\
3.5 \text { vol. } \%\end{array}$ & Laminar & $\begin{array}{l}32 \% \text { enhancement of with } \\
1.8 \text { vol. } \% \text { without major } \\
\text { friction loss }\end{array}$ \\
\hline $\begin{array}{l}\text { Jung, Natter, } \\
\text { Hempelmann \& } \\
\text { Lach (2009) }\end{array}$ & $\begin{array}{l}\mathrm{Al}_{2} \mathrm{O}_{3} \text {-water } 0.6-1.8 \\
\text { vol. } \% \mathrm{Al}_{2} \mathrm{O}_{3} \text {-water }\end{array}$ & $5-300$ & $+8 \%$ at 0.3 vol. $\%$ \\
\hline $\begin{array}{l}\text { Hwang, Lee, Park, } \\
\text { Park, Jung, Lee \& } \\
\text { Song (2009) }\end{array}$ & $0.01-0.3$ vol. $\%$ & $550-800$ & $\begin{array}{l}\text { Heat transfer } \\
\text { enhancement }\end{array}$ \\
\hline
\end{tabular}

Table 1. Results of papers published on different types of nanofluid. 
An experimental study was carried out by Yang (2005) who reported that nanoparticle concentration, material, temperature, and base fluid all affected the heat transfer coefficient. Bianco and Manca (2011) showed the effect of concentration on the heat transfer coefficient and Nusselt number with Reynolds number, as shown in Figure 4.

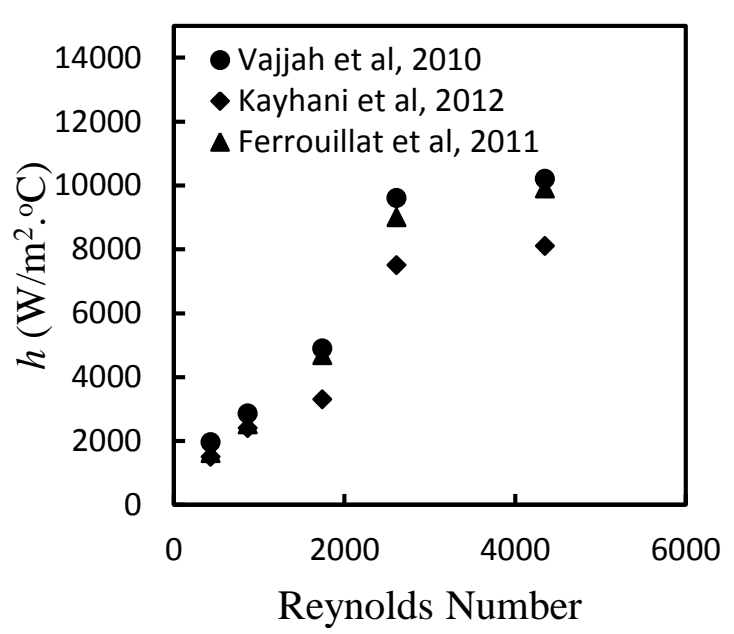

(a) Heat transfer coefficient

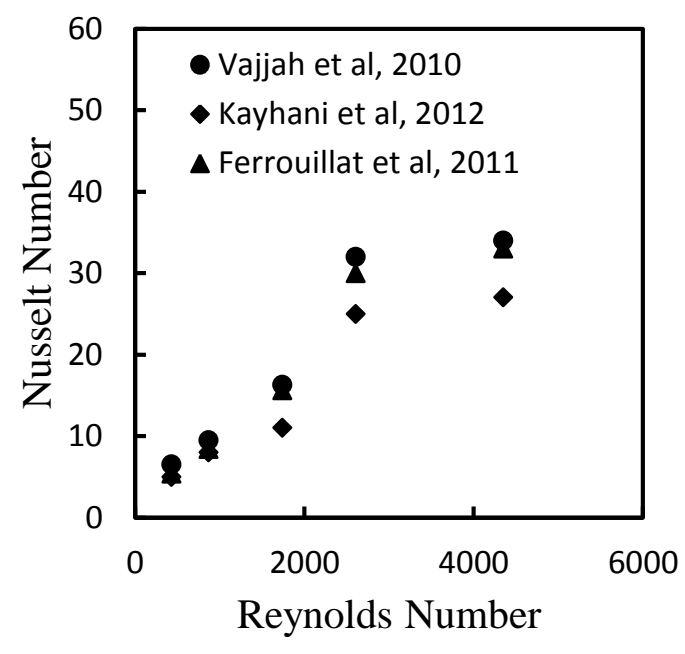

(b) Nusselt number

Figure 4. (a) heat transfer coefficient, (b) Nusselt number, at different Reynolds number.

\section{CONCLUSION}

The review of these studies shows that nanofluids are very important for many applications. Many studies showed good agreement between experimental and numerical studies. Some general conclusions are:

1. An increase in thermal conductivity occurred by adding nanoparticles to liquids.

2. Viscosity increased as the concentration of particles increased.

3. Friction factor increased with Reynolds number from experimental results and from the Blasius equation.

4. The convection heat transfer coefficient was shown to increase with Reynolds number and volume concentration by experimental results and the Dittus-Boelter equation.

5. There are many correlation equations among the input parameters (volume concentrations, Reynolds number, and temperature) and output parameters (friction factor and Nusselt number).

\section{ACKNOWLEDGMENTS}

The authors would like to thank the Universiti Malaysia Pahang for providing laboratory facilities and financial support. 


\section{REFERENCES}

Bhattacharya, P., Saha, S. K., Yadav, A., Phelan, P. E., \& Prasher, R. S. (2004). Brownian dynamics simulation to determine the effect thermal conductivity of nanofluids. Journal of Applied Physics, 95, 6492-6494.

Bianco, V., \& Manca, O. (2011). Numerical investigation on nanofluids turbulent convection heat transfer inside a circular tube. International Journal of Thermal Sciences, 50, 341-349.

Choi, S. U. S. (1995). Enhancing thermal conductivity of fluids with nanoparticles. Proceedings of the ASME International Mechanical Engineering Congress and Exposition, 99-105.

Dong, L., \& Leyuan, Y. (2010). Single-phase thermal transport of nanofluids in a minichannel. Department of Mechanical Engineering University of Houston Houston, TX 77004-4006 USA.

Eastman, J. A., Choi, S. U. S., Li, S., Thompson, L. J., \& Lee, S. (1997). Enhancement thermal conductivity through the development of nanofluids. Materials Research Society (MRS), Boston, USA.

Ferrouillat, S. (2011). Hydraulic and heat transfer study of $\mathrm{SiO}_{2} /$ water nanofluids in horizontal tubes with imposed wall temperature boundary conditions. International Journal of Heat and Fluid Flow, 32, 424-439.

Gianluca, P. (2012). Properties of $\mathrm{Au}-\mathrm{H}_{2} \mathrm{O}$ nanofluids using molecular dynamics. $\mathrm{PhD}$ thesis, Aerospace and Mechanical Engineering dept., University of Notre Dame.

Heris, S. Z., Etemad, G., \& Esfahany, M. N. (2006). Experimental investigation of oxide nanofluids laminar flow convection heat transfer. International Communications in Heat and Mass Transfer, 33, 529-535.

Hwang, S., Lee, J., Park, S., Park, D. R., Jung, J. C., Lee, S. B., \& Song, I. K. (2009). Production of Middle Distillate through Hydrocracking of Paraffin Wax over $\mathrm{NiMo} / \mathrm{SiO}_{2}-\mathrm{Al}_{2} \mathrm{O}_{3}$ Catalysts: Effect of $\mathrm{SiO}_{2}-\mathrm{Al}_{2} \mathrm{O}_{3}$ Composition on Acid Property and Catalytic Performance of $\mathrm{NiMo} / \mathrm{SiO}_{2}-\mathrm{Al}_{2} \mathrm{O}_{3}$ Catalysts. Catalysis letters, 129, 163-169.

Incropera, F. P., \& DeWitt, D. P. (1996). Fundamentals of Heat and Mass Transfer. John Wiley \& Sons, NY.

Jung, A., Natter, H., Hempelmann, R., \& Lach, E. (2009). Nanocrystalline alumina dispersed in nanocrystalline nickel: enhanced mechanical properties. Journal of Materials Science, 44(11), 2725-2735.

Kulkarni, D. P., Namburu, P. K., Ed Bargar, H., \& Das, D. K. (2008). Convective heat transfer and fluid dynamic characteristics of $\mathrm{SiO} 2$ ethylene glycol/water nanofluid, Heat Transfer Engineering, 29, 1027-1035.

Lee, S., \& Choi, S. U. S. (1996). Application of metallic nanoparticle suspensions in advanced cooling systems. Argonne National Lab., IL (United States), (630), 2526439.

Lee, S., Choi, S. U. S., Li, S. A., \& Eastman, J. A. (1999). Measuring thermal conductivity of fluids containing oxide nanoparticles. Journal of Heat Transfer, 121(2), 280-289.

Li, Q., \& Xuan, Y. (2002). Convective heat transfer and flow characteristics of Cuwater nanofluid. Science in China Series E: Technolgical Science, 45(4), 408-416.

Ma, H. B., Wilson, C., Borgmeyer, B., Park, K., \& Yu, Q. (2006). Effect of nanofluid on the heat transport capability in an oscillatory heat pipe. Applied Physics Letters, 88: 143116(3). 
Masuda, H., Ebata, Teramae, A., \& Hishinuma, K. N. (1993). Alteration of thermal conductivity and viscosity of liquid by dispersing ultra-fine particles (Dispersion of $\mathrm{Al}_{2} \mathrm{O}_{3}, \mathrm{SiO}_{2}$ and $\mathrm{TiO}_{2}$ ultra-fine particles), Netsu Bussei, 7, 227-233.

Namburu, P. K., Kulkarni, D. P., Misra, D., \& Das, D. K. (2007). Viscosity of copper oxide nanoparticles dispersed in ethylene glycol and water mixture. Experimental Thermal and Fluid Science., 32(2), 397-402.

Nguyen, C., Desgranges, F., Galanis, N., Roy, G., Mare, T., Boucher, S., \& Angue, M. (2008). Viscosity data for Al2O3water nanofluid-hysteresis: is heat transfer enhancement using nanofluids reliable? International Journal of Thermal Sciences, 47(2), 103-111.

Pak, B. C., \& Cho, Y. I. (1998). Hydrodynamic and heat transfer study of dispersed fluids with submicron metallic oxide particles, Experimental Heat Transfer, 11, 151-170.

Pawan, K., Singh, K. B., \& Anoop, H. E. (2010). Anomalous size dependent rheological behavior of alumina based nanofluids. International Journal of Micro-Nano Scale Transport, 1(2): 179-188.

Pozhar, L. A. (2000). Structure and dynamics of nanofluids: theory and simulations to calculate viscosity. Physical Review E, 61, 1432-1446.

Prasher, R. Song, D., Wang, J., \& Phelan, P. (2006). Measurements of nanofluid viscosity and its implications for thermal applications. Applied Physics Letters, 89(13), 133108.

Rao, G. S., Sharma, K. V., Chary, S. P., Bakar, R. A., Rahman, M. M., Kadirgama, K., \& Noor, M. M. (2011). Experimental Study on heat transfer coefficient and friction factor of A12O3 nanofluid in a packed bed column. Journal of Mechanical Engineering and Sciences, 1, 1-15.

Rea, U., McKrell, T., Hu, L. W., \& Buongiorno, J. (2009). Laminar convective heat transfer and viscous pressure loss of alumina-water and zirconia-water nanofluids. International Journal of Heat and Mass Transfer, 52(7), 2042-2048.

Shuichi, T. (2012). Turbulent heat transfer behavior of nanofluid in a circular tube heater under constant heat flux. Advance in Mechanical Engineering, article ID 917612 (7 pages).

Suresh, S., Venkitaraj, K.P., Selvakumar, P., \& Chandrasekar, M. (2012). Effect of $\mathrm{Al} 2 \mathrm{O} 3-\mathrm{Cu} /$ water hybrid nanofluid in heat transfer. Experimental Thermal and Fluid Science, 38, 54-60.

Syam Sundar, L., \& Sharma, K.V. 2011a. Laminar convective heat transfer and friction factor of $\mathrm{Al} 2 \mathrm{O} 3$ nanofluid in circular tube fitted with twisted tape inserts. International Journal of Automotive and Mechanical Engineering, 3, 265-278.

Syam Sundar, L., \& Sharma, K. V. (2011b). A numerical study heat transfer and friction factor of A12O3 nanofluid. Journal of Mechanical Engineering and Sciences, 1, 99-112.

Timofeeva, E. V., Yu, W., France, D. M., Singh, D., \& Routbort, J. L.(2010). Base fluid and temperature effects on the heat transfer characteristics of $\mathrm{SiC}$ in $\mathrm{EG} / \mathrm{H}_{2} \mathrm{O}$ and $\mathrm{H}_{2} \mathrm{O}$ nanofluids. Journal of Applied Physics, 109, 014914 (5 pages).

Vijaya Lakshmi, B., Subrahmanyam, T., Dharma Rao, V., \& Sharma, K. V. (2012). Turbulent film condensation of pure vapors flowing normal to a horizontal condenser tube - constant heat flux at the tube wall. International Journal of Automotive and Mechanical Engineering, 4, 455-470.

Vold, I. M. N., Kristiansen, K. A., \& Christensen, B. E. (2006). A study of the chain stiffness and extension of alginates, in vitro epimerized alginates, and periodate- 
oxidized alginates using size-exclusion chromatography combined with light scattering and viscosity detectors. Biomacromolecules, 7(7), 2136-2146.

Wang, Z. (2009). Thermal wave in thermal properties measurements and flow diagnostics: with applications of nanofluids thermal conductivity and wall shear stress measurements. PhD thesis, Oregon State University.

Wen, D., \& Ding, Y. (2004). Experimental investigation into convective heat transfer of nanofluids at the entrance region under laminar flow conditions. International Journal of Heat and Mass Transfer, 47(24), 5181-5188.

Xuan, Y., \& Li, Q. (2002). Investigation convective heat transfer and flow features of nanofluids. Journal of Heat Transfer, 125, 151-155.

Xuan, Y., \& Li, Q. (2000). Heat transfer enhancement of nanofluids. International Journal of Heat and Fluid Flow, 21, 58-64.

Xuan, Y., \& Roetzel, W. (2000). Conceptions for heat transfer correlation of nanofluids, International Journal of Heat and Mass Transfer, 43, 3701-3707.

Xue, L., Keblinski, P., Phillpot, S. R., Choi, S. U. S., \& Eastman, J. A. (2004). Effect of liquid layering at the liquid-solid interface on thermal transport. International Journal of Heat and Mass Transfer, 47, 4277-4284.

Yang, Y., Zhang, Z.G., Grulke, E. A., Anderson, W. B., \& Wu, G. (2005). Heat transfer properties of nanoparticle-in-fluid dispersions (nanofluids) in laminar flow, International Journal of Heat and Mass Transfer, 48, 1107-1116.

Zeinali, H., Esfahany, N., \& Etemad, S.G. (2007). Experimental investigation of convective heat transfer of $\mathrm{Al}_{2} \mathrm{O}_{3}$ /water nanofluid in circular tube. International Journal of Heat and Fluid Flow, 28(2), 203-210.

\section{NOMENCLATURE}

$C$ specific heat capacity $\left(\mathrm{J} / \mathrm{kg} .{ }^{o} \mathrm{k}\right)$

$d$ diameter of tube $(m)$

$f$ friction factor

$h$ heat transfer coefficient $\left(W / m^{2}{ }^{\circ} \mathrm{C}\right)$

$k$ thermal conductivity $\left(\mathrm{W} / \mathrm{m} .{ }^{\circ} \mathrm{C}\right)$

$N u$ Nusselt number $\left(N u=\frac{h \times d}{k}\right)$

$P e$ Peclet number $(P e=R e P r)$

$\operatorname{Pr}$ Prandtl number $\left(\operatorname{Pr}=\frac{C \times \mu}{k}\right)$

$R e$ Reynolds number $\left(\operatorname{Re}=\frac{\rho \times v \times d}{\mu}\right)$

$v$ velocity of fluid $(\mathrm{m} / \mathrm{s})$

$\phi$ concentration of solid particles

$\mu$ Viscosity (Pa.s)

$\rho$ Density $\left(\mathrm{kg} / \mathrm{m}^{3}\right)$

\section{SUBSCRIPTS}

av average value

$f$ fluid

nf nanofluid

$s$ solid 